\title{
Awareness for need of improvement in knowledgement about oral lesions for professionals in primary health care
}

\author{
Priscila Cristina de Paula Alves, ${ }^{1}$ Leandro Dorigan de Macedo, ${ }^{1}$ Soraya Fernandes Mestriner, ${ }^{3}$ Hilton Marcos Alves Ricz, ${ }^{2}$ Daiane Leite da Roza, ${ }^{4}$ Luiz Carlos \\ Conti de Freitas, ${ }^{2}$ Lara Maria Alencar Ramos Innocentini ${ }^{1}$ \\ ${ }^{1}$ Division of Dentistry and Stomatology, Ribeirão Preto Clinical Hospital, Ribeirão Preto School of Medicine, University of São Paulo, Ribeirão Preto, SP, Brazil \\ 2Division of Head and Neck Surgery, Ophthalmology, Otorhinolaryngology and Head and Neck Surgery Department, Ribeirão Preto Clinical Hospital, Ribeirão Preto \\ School of Medicine, São Paulo University, Ribeirão Preto, SP, Brazil \\ ${ }^{3}$ Department of Stomatology, Public Oral Health and Forensic Dentistry, Division of Oral Diagnosis, School of Dentistry of Ribeirão Preto, University of São Paulo, \\ Ribeirão Preto, SP, Brazil \\ ${ }^{4}$ Department of Social Medicine, Ribeirão Preto School of Medicine, University of São Paulo, Ribeirão Preto, SP, Brazil \\ - Conflicts of interest: none declared.
}

\section{Abstract}

Objective: this study aims to evaluate the efficacy of diagnosis and treatment of oral lesions between different healthcare levels. Material and Methods: all information was obtained from the medical records of a University Hospital and Public Health Regulation System regarding clinical-demographic features such as oral diseases diagnosed, referral system and therapy employed. Evaluation was based on the relationship between final diagnosis, diagnostic hypothesis and the priority of medical appointments, time between referral and first appointment, date of final diagnosis and therapy onset. Latter, diagnostic hypothesis fulfilled between primary and tertiary healthcare providers were compared and the agreement between both were determined. Results: about half (51\%) of the medical forms filled by primary healthcare professionals were incomplete, or diagnostic hypothesis was inadequately described. At the tertiary healthcare level, mean time between referral and first appointment was 23 days, and mean time between the final diagnosis and treatment was 22 days. Surgical treatment was faster (31 days) when compared to radiotherapy for malignant lesions (81 to 100 days). Conclusion: it is necessary to improve training of healthcare professionals in the primary healthcare regarding the recognition of malignant oral lesions. Clearly, appropriate filling of the diagnostic hypothesis with the corresponding degree of priority accelerates the diagnosis and treatment of the patient.

Keywords: Oral diagnosis; Healthcare providers; Prevention.

\section{Introduction}

$\mathrm{O}$ ral lesions are caused by internal and external factors, including local trauma, infections, metabolic and immunological changes. ${ }^{1,2}$ Moreover, personal features such as, race gender, exposure to risk factors, and patient's general health might predict the risk of disease development. ${ }^{3,4}$ Among these conditions, benign oral lesions, although involving a low risk of death, may cause extensive local destruction or compression of noble structures, compromising normal functions. Otherwise, malignant tumours are associated with high morbidity and mortality rates. $^{2}$

Although oral cavity can be easily examined, in Brazil the oral cancer is usually diagnosed late, with the consequent need for aggressive and mutilating treatments that aggravate the prognosis and impair patient's social life..$^{5-8}$ Primary healthcare professionals play an important role in the early diagnosis of these conditions because of their routine contact with the patient and the possibility to identify and monitor important changes in risk groups. These policies of health education and preventive care allow the patient to look for a health service when he notes any changes. Thus, when necessary, professionals of the primary healthcare staff refer the patients to specialized units for a definitive diagnosis and treatment. ${ }^{1}$
Clinical features of lesions referred to specialized services is quite varied and reflects the preparation of primary healthcare professionals in indicate the severity of oral lesions. ${ }^{9}$ Some studies have shown that dental surgeons and generalist doctors are poorly prepared to identify and deal with changes in the oral cavity, with a consequent delay in the diagnosis of oral diseases. ${ }^{5,6}$ Resulting in patients' referral even when they present easy resolution lesions or variations of the normality in oral mucosa, delaying the prompt care of patients who actually have severe changes.

Thus, the objective of the present study was to determine the efficacy of referrals from the Primary Healthcare Service to a reference center of oral diagnosis and treatment in a School Hospital. Second, evaluate the agility of the tertiary healthcare center in making a diagnosis and providing treatment.

\section{Material and Methods}

This was a retrospective study based on the review of documents submitted by the System of Support and Assistance Regulation (SARA in the Portuguese acronym) and on the survey of data from the medical records of patients seen at the Outpatient Clinic for the Prevention of Oral Cancer and Stomatology (APCBE). The APCBE is a multidisciplinary outpatient clinic staffed by Head and Neck 
Surgeons, a Stomatologist Dental Surgeon and an Otorhinolaryngologist, focused in diagnosis and treatment of oral lesions and correlated structures. The study was approved by the Research Ethics Committee of the University Hospital $\left(n^{\circ} 1.575 .317\right)$.

The procedure for the scheduling of the first consultation at the APCBE is based on the assessment by the tertiary healthcare professionals of fulfilled forms inserted in the SARA by the primary healthcare professionals. All visits at the Hospital are recorded in the electronic system of the institution. On this basis, the health care process for these patients involves various levels and the final result of the care provided depends on the effectiveness of each one of them.

All patients enrolled in this study were referred by the SARA system for evaluation at the APCBE from January 2014 to July 2016. Inclusion criteria were patients with oral lesions over 18-year-old. Exclusion criteria were patients who had not been referred by the SARA system, patients referred to other services for treatment, patients who failed to attend the first visit at the APCBE and/or who had no record in the SARA system.

The demographic data obtained from the medical records were organized on Excel spreadsheets and defined as categorical variables, age, gender, ethnic, educational level, and presence of smoking and drinking habits.

Analysis of the adequacy of the initial referral was based on the supply of all data requested at form. Preparation of the professionals of the primary healthcare regarding the distinction between premalignant, malignant and benign lesions was assessed on the basis of the frequency of agreement between the final diagnosis and the diagnostic hypothesis and of the correlation between the final diagnosis and the initial priority identified at referral.

The flow and assertiveness

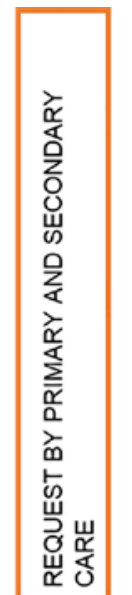

of the care provided by APCBE was assessed on the basis of the frequency of agreement between the diagnostic hypothesis raised at the initial visit and the definitive diagnosis obtained after the histopathological analysis, when conducted.

Efficacy of flow through the health service network was evaluated by counting the time, in days, needed for the execution of each stage of the process: 1 - from the referral issued by the primary healthcare to the first visit at APCBE; 2 - from the first visit at APCBE to the final diagnosis; 3 - from the final diagnosis to the beginning of treatment. All of these stages are illustrated in Figure 1. This evaluation permitted the identification of steps associated with possible delays in assistance provided to this population. To determine the waiting time until the adjuvant treatments including radiotherapy and

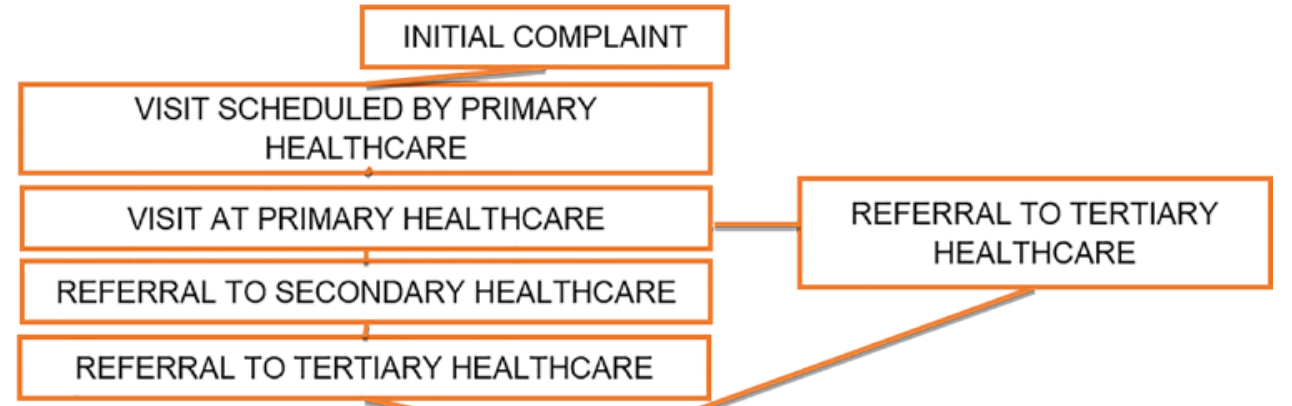

DIAGNOSTIC HYPOTHESIS AND DEFINITION OF PRIORITY

SENDING THE REFERRAL TO THE CENTER OF VACANCY REGULATION

INSERTION OF THE REQUEST IN THE SARA SYSTEM

EVALUATION OF THE REQUEST IN THE SARA SYSTEM BY THE TERTIARY HEALTHCARE PROFESSIONAL

ACCEPTANCE BY THE EMPLOYEE, MAINTENANCE OR REDEFINITION OF PRIORITY

SCHEDULING OF VACANCY AND PATIENT NOTIFICATION BY THE REGULATION CENTER

INITIAL VISIT AT APCBE: BEGINNING OF INVESTIGATION

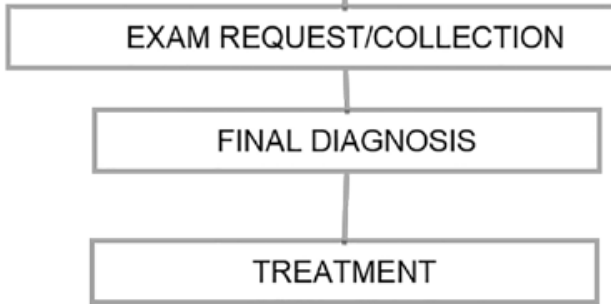

Figure 1. Flow diagram for the referral of oral lesions from the primary to the tertiary healthcare 
chemotherapy, we considered the time elapsed from surgery.

Data were analysed using descriptive statistics. The basic objective of this methodology was to synthesize a series of values of the same nature, allowed a global view of the variation in these values, with the data being organized and described in three ways, i.e., by means of tables, graphs and descriptive measures. ${ }^{10}$

\section{Results}

Out of a total of 379 patients scheduled at APCBE, 252 were included in the study (50.4\%) men and (49.6\%) women. Clinical-demographical data are organized in Table 1 according to the final diagnosis. There was a prevalence of women in the group of benign lesions, while men predominated in the group of malignant lesions.

Table 1. Epidemiological profile of the lesions of patients referred to the tertiary level

\begin{tabular}{|c|c|c|c|c|c|c|}
\hline & $\begin{array}{l}\text { Lesion/ } \\
\text { Total (\%) }\end{array}$ & $\begin{array}{c}\text { Benign } \\
159(63 \%)\end{array}$ & $\begin{array}{l}\text { Malignant } \\
58(23 \%)\end{array}$ & $\begin{array}{c}\mathrm{PM}^{\mathrm{A}} \\
17(6.7 \%)\end{array}$ & $\begin{array}{c}\text { Absence of lesion } \\
12(4.8 \%)\end{array}$ & $\begin{array}{c}\text { No information } \\
6(2.4 \%)\end{array}$ \\
\hline \multicolumn{7}{|c|}{ Gender } \\
\hline \multicolumn{2}{|l|}{$\mathrm{M}(50.4 \%)$} & 66 & 43 & 10 & 7 & 1 \\
\hline \multicolumn{2}{|l|}{$F(49.6 \%)$} & 93 & 15 & 7 & 5 & 5 \\
\hline \multicolumn{7}{|c|}{ Age } \\
\hline \multirow{2}{*}{$\begin{array}{l}\text { Mean: } 54 \\
\text { Median: } 57\end{array}$} & $0-49$ years $(32.5 \%)$ & 64 & 10 & 4 & 2 & 2 \\
\hline & $\geq 50$ years $(67.5 \%)$ & 95 & 48 & 13 & 10 & 4 \\
\hline \multicolumn{7}{|c|}{ Skin Color } \\
\hline \multicolumn{2}{|l|}{ White (91\%) } & 144 & 53 & 15 & 11 & 6 \\
\hline \multicolumn{2}{|c|}{ Mulatto (5\%) } & 7 & 3 & 2 & 0 & 0 \\
\hline \multicolumn{2}{|l|}{ Black (4\%) } & 8 & 2 & 0 & 1 & 0 \\
\hline \multicolumn{7}{|c|}{ Level Educational } \\
\hline \multicolumn{2}{|c|}{ Elementary (45\%) } & 73 & 24 & 10 & 5 & 2 \\
\hline \multicolumn{2}{|c|}{ High school (7\%) } & 14 & 1 & 1 & 0 & 0 \\
\hline \multicolumn{2}{|c|}{ Higher education (2\%) } & 2 & 3 & 0 & 0 & 0 \\
\hline \multicolumn{2}{|c|}{ Literate (42\%) } & 70 & 21 & 4 & 7 & 4 \\
\hline \multicolumn{2}{|c|}{ No information ${ }^{c}(4 \%)$} & 0 & 9 & 2 & 0 & 0 \\
\hline \multicolumn{7}{|c|}{ Mean duration of complaint (months) } \\
\hline & & 22 & 6 & 16 & 11 & 9 \\
\hline \multicolumn{7}{|c|}{ Habits } \\
\hline \multicolumn{2}{|l|}{ Smoker } & 34 & 36 & 5 & 2 & 1 \\
\hline \multicolumn{2}{|l|}{ Drinker } & 17 & 26 & 2 & 2 & 1 \\
\hline \multicolumn{2}{|l|}{ Ex-Smoker } & 19 & 10 & 5 & 2 & 1 \\
\hline \multicolumn{2}{|l|}{ Ex-Drinker } & 19 & 10 & 5 & 2 & 0 \\
\hline \multicolumn{2}{|l|}{ Denies } & 39 & 7 & 3 & 2 & 2 \\
\hline \multicolumn{2}{|c|}{ Drug addiction } & 1 & 1 & 0 & 0 & 0 \\
\hline \multicolumn{2}{|c|}{ No information ${ }^{c}$} & 49 & 5 & 4 & 2 & 1 \\
\hline
\end{tabular}

A. Potentially malignant disorders: Leucoplakia, Erythroplakia and Actinic Cheilitis.

B. Patients who did not exhibit lesions during clinical examination.

c. Data not detected. 
Regarding age, there was a prevalence of age ranges of 50 years or more. As shown in Table 1, there was a prevalence of white subjects $(144 ; 91 \%)$. Among cases referred to APC$\mathrm{BE}$, benign lesions predominated in the final diagnosis $(\mathrm{n}=$ 159), corresponding to $63 \%$ of the referrals. Moreover, $4.8 \%$ of lesions had disappeared up to first visit at the outpatient clinic.

Part of the patients (42\%) declared that they were illiterate. About 45\% reported having completed elementary school, $6 \%$ declared having completed high school, and $2 \%$ reported complete higher education. The mean time between the onset of the lesion and looking for care (as reported by the patient) was shorter for malignant lesions (six months) and longer for benign lesions (22 months).

Considering habits, most of patients with malignant lesions 46 (78\%) reported current or previous smoking at some time in life.

Table 2 lists the referrals according to the diagnostic hypothesis and the priority appointed for the primary healthcare and the final diagnosis, the priority and the final diagnosis. Among the hypotheses of malignant lesions raised by the primary level, one case was considered to be of low priority and another one arrived at the tertiary level with no lesion. In 129 (51\%) referrals the primary health care professional did not fill out the hypothesis or wrote it in an inappropriate manner. Only 27 (55\%) lesions referred as malignant by the primary level were confirmed as malignant in the histopathological exam. In contrast, for 59 (91\%) of the lesions referred as benign the diagnostic hypothesis of the primary healthcare was compatible with the final diagnosis.
Many of the hypotheses raised on the occasion of the first visit at APCBE were compatible with the final diagnosis. Of the 41 cases referred for histopathological analysis of a suspected malignancy, $90 \%$ were confirmed as malignant, and $98 \%$ of the cases with suspected benign lesions were positive.

In 38 cases, there was no description of the diagnostic hypothesis of the tertiary level in the information system of the hospital. In six cases the diagnostic hypothesis was inadequate. A total of 137 biopsies were performed and imaging exams were requested to complement the diagnosis. The exam most frequently requested after the histopathological analysis was tomography, with a waiting period of 9 days (data not shown).

Time elapsed for each stage from the request of referral by the primary healthcare to treatment (when needed) is presented in Table 3. For the stage between referral and the 1st visit, the shortest time was for malignant lesions, 20 days on average, whereas the time until the beginning of treatment for these lesions was the longest, 55 days on average. For benign lesions the most rapid time was between diagnosis and treatment, approximately 5 days.

As shown in Figure 2, the mean waiting time for cases submitted to exclusive surgery as oncologic treatment was 31 days. This reduced time compared to other instituted treatments was due to the fact that effective treatment was performed with the excisional biopsy itself on the occasion of the first visit, and in specific cases of small tumours the time between diagnosis and treatment was zero. In contrast, the mean time until surgical treatment associated with radiotherapy and/or chemotherapy was 51 days.

Table 2. Diagnostic hypothesis and priority of the primary and secondary levels of healthcare compared to the final diagnosis made at the tertiary level

\begin{tabular}{|c|c|c|c|c|c|c|c|c|}
\hline \multirow{2}{*}{$\begin{array}{l}\text { Diagnostic } \\
\text { Hypothesis raised in the } \\
\text { Primary healthcare (n) }\end{array}$} & \multicolumn{3}{|c|}{ Priority } & \multicolumn{5}{|c|}{ Final Diagnosis } \\
\hline & High (n) & Medium (n) & Low (n) & $\mathrm{PM}^{\mathrm{A}}(\%)$ & $\begin{array}{c}\text { Malignant } \\
(\%)\end{array}$ & $\begin{array}{c}\text { Benign } \\
(\%)\end{array}$ & $\begin{array}{c}\text { No } \\
\text { Lesion }^{\mathrm{D}}(\%)\end{array}$ & $\operatorname{NDC}^{C}(\%)$ \\
\hline Malignant (49) & 42 & 6 & 1 & $3(6)$ & $27(55)$ & $17(35)$ & $1(2)$ & $1(2)$ \\
\hline Benign (64) & 12 & 28 & 23 & $1(1.5)$ & 0 & $59(91)$ & $4(6)$ & $1(1.5)$ \\
\hline $\mathrm{PM}^{\mathrm{A}}(10)$ & 2 & 6 & 2 & $2(10)$ & $1(10)$ & $6(70)$ & $1(10)$ & 0 \\
\hline $\mathrm{HDI}^{\mathrm{B}}(63)$ & 36 & 18 & 9 & $8(13)$ & $18(28,5)$ & $35(55.5)$ & $1(1.5)$ & $1(1.5)$ \\
\hline $\operatorname{NDC}^{C}(66)$ & 22 & 36 & 8 & $4(6.0)$ & $12(18)$ & $41(62)$ & $6(9)$ & $3(5)$ \\
\hline
\end{tabular}

A. Potentially Malignant: leucoplakia, erythroplakia and actinic cheilitis.

B. Incomplete or incoherent diagnostic hypothesis described in the referral chart of the primary healthcare service.

c. Information not found.

D. Did not show a lesion at the time of the exam. 
Table 3. Time (days) between periods of care for malignant, benign and potentially malignant lesions

\begin{tabular}{|c|c|c|c|c|c|c|}
\hline \multicolumn{2}{|c|}{ Final Diagnosis } & \multirow{2}{*}{$\frac{\text { Mean }}{24.6}$} & \multirow{2}{*}{$\begin{array}{c}\text { Standard deviation } \\
22.4\end{array}$} & \multirow{2}{*}{$\frac{\text { Minimum }}{0.0}$} & \multirow{2}{*}{$\begin{array}{c}\text { Median } \\
19.0\end{array}$} & \multirow{2}{*}{$\begin{array}{c}\text { Maximum } \\
159.0\end{array}$} \\
\hline \multirow{3}{*}{$\begin{array}{l}\text { 1st Period } \\
\text { (days) }\end{array}$} & Benign & & & & & \\
\hline & Malignant & 19.4 & 9.3 & 6.0 & 15.0 & 43.0 \\
\hline & Potentially malignant ${ }^{A}$ & 23.7 & 14.0 & 5.0 & 22.0 & 56.0 \\
\hline \multirow{3}{*}{$\begin{array}{l}\text { 2nd Period } \\
\text { (days) }\end{array}$} & Benign & 56.1 & 68.9 & 0.0 & 42.0 & 489.0 \\
\hline & Malignant & 30.6 & 34.4 & 0.0 & 21.0 & 195.0 \\
\hline & Potentially malignant & 54.8 & 58.0 & 0.0 & 40.5 & 203.0 \\
\hline \multirow{3}{*}{$\begin{array}{l}\text { 3rd Period } \\
\text { (days) }\end{array}$} & Benign & $4.7^{\mathrm{B}}$ & 37.8 & 0.0 & 0.0 & 316.0 \\
\hline & Malignant & 54.3 & 39.5 & 0.0 & 50.5 & 174.0 \\
\hline & Potentially malignant & 7.9 & 16.8 & 0.0 & 0.0 & 49.0 \\
\hline
\end{tabular}

1st Period: Between referral and the 1st visit (tertiary level).

2nd Period: From the 1st visit at the tertiary level to the final diagnosis.

3rd Period: From the final diagnosis to treatment.

A. Potentially Malignant Lesions: Leukoplakia, Erythroplakia and Actinic Cheilitis.

B. Many benign lesions were treated by removal (excisional biopsy) on the first day of the tertiary level visit. Thus, the time from diagnosis to final treatment was considered to be 0 .

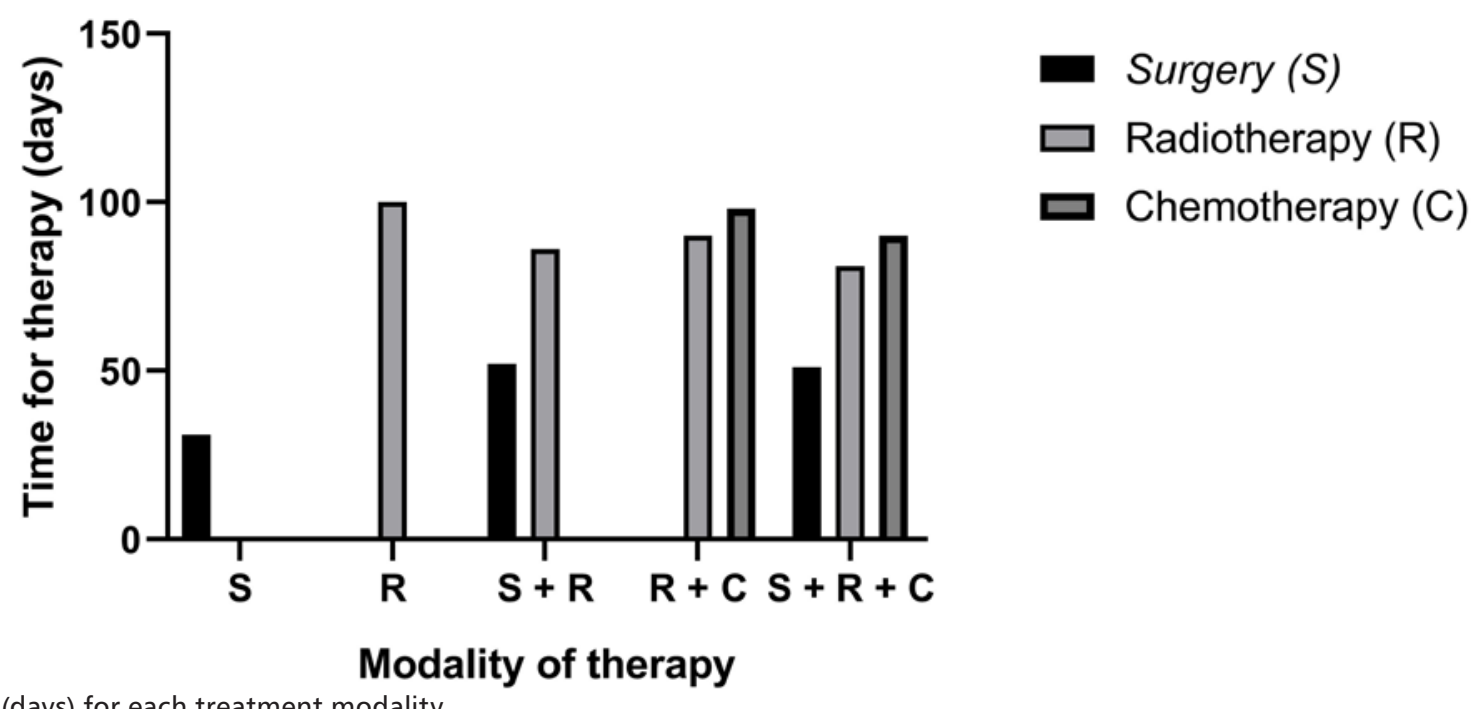

Figure 2. Time (days) for each treatment modality

The waiting time until surgery, radiotherapy and chemotherapy were 51, 81 and 90 days, respectively Figure 2. In protocols in which the therapy of choice was surgery plus adjuvant radiotherapy the waiting time was 52 and 86 days, respectively. In cases in which radiotherapy was the treatment of choice due to contraindication of surgery or to the choice of the patient himself, the waiting time was 100 days from the indication of the procedure.

\section{Discussion}

Benign lesions were the most frequent diagnoses made at the tertiary level, in agreement with Diebold and Overbeck, ${ }^{11}$ who pointed out that these are the most prevalent lesions in the oral cavity. According to various studies, the prevalence of malignant lesions is more frequent among males, as also confirmed by the present results. However, some studies have shown that the incidence of oral cancer is increasing among women due to changes in their habits. ${ }^{12-14}$

Patients referred were frequently middle-aged or elderly. This result agrees. With the literature ${ }^{13,15}$ since there is evidence of a higher incidence of neoplasia among these individuals due to the various physiological changes related to aging. Which in parallel determine molecular and genetic changes and deregulation or insufficiency of the immunological system, favouring cell proliferation and the possible onset of cancer in the elderly. ${ }^{15}$

Strongly correlated, smoking and drinking have a strong impact on the development of malignant lesions. ${ }^{16,13}$ In the 
present population, many subjects diagnosed with a malignant lesion (46 of 58 cases) were smokers or ex-smokers. Alcohol intake was also more frequent among these patients (33 subjects were still consuming alcohol or had chronically consumed it in the past).

The time elapsed from the onset of a lesion to the search for treatment is a decisive element for the prognosis of the disease. When this time is short it permits a less aggressive and mutilating treatment, in addition to increasing the chance of survival. ${ }^{17}$ The period of time until treatment includes the beginning of symptoms felt by the patient, looking for a professional, the final diagnosis and the beginning of therapy. There are two characteristics in this story: the patient himself and the health professional. While a delay of professional care can be measured in a more precise manner, the delay of the patient in seeking care tends to be equivocal, since it is subjective and is related to the degree of self-perception. ${ }^{8}$

In the present study, the time from the onset of symptoms to the search for care was 6 months among subjects with a diagnosis of a malignant tumour. This was a shorter time than that reported in the study by Felippu et al. ${ }^{18}$ which was 10 months. For benign lesions, there was a longer time of 22 months, which can be explained by the slow course and low risk characteristic of these lesions. ${ }^{13}$

Although the mouth is an anatomical site of easy access for examination, many oral tumours are identified in advanced stages. ${ }^{1}$ Some of the factors related to this occurrence are the absence of symptoms in initial lesions and patient neglect regarding his symptoms. In this second situation, the educational level of the patient has an important influence. In the present study, most of the patients had a low educational level, leading to a lesser understanding of the course of the disease. ${ }^{9}$

The health professionals of the primary healthcare are little prepared to identify the lesions and, in many places, access to healthcare system is deficient due to the absence of government programs for prevention and health education and of a more efficient health system. ${ }^{4,6,8}$

In many requests forwarded by professionals of the primary health care service the diagnostic hypothesis had not been filled out or had been filled out inappropriately, without a valid hypothesis. Also, the definition of priority was poorly correlated with the hypothesis. An example was a case of suspected malignancy which, however, was classified as being of low priority. In 12 cases, including one subject with the hypothesis of a malignant lesion, the lesion had disappeared on the occasion of the first visit at the tertiary level.

Of the 49 cases referred by the primary healthcare as malignant, only 27 (55\%) were confirmed. Among the 66 cases with an inadequate hypothesis, 18 involved malig- nant lesions and 12 had no hypothesis. These data suggest lack of preparation on the part of the professionals of the primary healthcare for the identification and diagnosis of oral lesions. In addition, this information helps the professionals of the tertiary network who receive these referrals and accept screening, determining the degree of urgency, or who return the patients erroneously referred to the service. The time intervals between the referral stage and the 1st visit at the tertiary level, the final diagnosis and treatment were shorter when compared to the study by Felippu et al. ${ }^{18}$ whereas the interval between the 1st visit and the final diagnosis was similar. Also, the time for all the stages of the present study was shorter than that reported in the study by Le Campion et al. ${ }^{9}$

The diagnostic hypotheses raised during the first visit at APCBE were strongly compatible with the final diagnosis, permitting a prompt treatment of the lesions. Many benign lesions were biopsied with complete excision on this first day and were considered to have been treated, contributing to reduction of the number of days between diagnosis and treatment. When malignancy was suspected, the biopsy was performed during the first visit in order to confirm the diagnosis and complementary exams were requested for staging.

In contrast, the beginning of treatment of malignant lesions was usually more delayed since it involved more steps for execution such as a sequence of complementary exams, anaesthesiology team releasing and surgical planning. ${ }^{1,6,19}$ The treatments indicated were only surgery or only radiotherapy, radiotherapy plus chemotherapy, or a combination of surgery, radiotherapy and chemotherapy. Surgical treatment was the most rapid, applied on average 31 days after the final diagnosis. In contrast, radiotherapy involved the longest delay, with a variation of 81 to 100 days according to the type of treatment (surgery plus radiotherapy; surgery plus radiotherapy and chemotherapy; radiotherapy plus chemotherapy, and radiotherapy alone).

Since chemotherapy should be applied concomitantly with radiotherapy, ${ }^{19,18}$ the patient needs to wait for radiotherapy in order to receive chemotherapy. On this basis, the times of association of the two modalities were similar. According to studies, the ideal interval between surgery and the beginning of radiotherapy is up to 6 weeks (42 days)..$^{20,21}$ A delay in the initiation of adjuvant radiotherapy impairs disease control and favours the repopulation of tumour cells followed by relapse of the disease. ${ }^{20,21}$ Thus, a delayed beginning of these therapies can reduce the cure rates and the effectiveness of treatment. ${ }^{17,20,19}$

\section{Conclusion}

Disagreement detected in the present study between the diagnostic hypothesis for malignant lesions at the pri- 
mary healthcare and the final diagnosis suggests that the professionals need more capacitation programs. Moreover, through knowledge improvement about clinical characteristics of benign and malignant oral lesions might be benefit in public polices to prevent oral cancer.

\section{Acknowledgments}

The authors wish to thank the Department of Ophthalmology, Otorhinolaryngology and Head and Neck Surgery and the financial support provided by the Fundação de Apoio ao Ensino, Pesquisa e Assistência (FAEPA).

\section{References}

1. Gheno JN, Martins MAT, Munerato MC, Hugo FN, Filho MS, Weissheimer C, et al. Oral mucosal lesions and their association with sociodemographic, behavioral, and health status factors. Braz Oral Res. 2015;29(1):1-6.

2. Saintrain MVL, Bandeira ABV, Pequeno LL, Bizerril DO, Marques PLP, Viana FAC. Oral health of older people: tracking soft tissue injuries for the prevention of oral cancer. Rev Esc Enferm. 2018;52:e03380.

3. Silk H. Diseases of the mouth. Prim Care. 2014;41(1):75-90.

4. Esmaelbeigi F, Hadji M, Harirchi I, Omranipour R, Rajabpour MV, Zendehdel K. Factors affecting professional delay in diagnosis and treatment of oral cancer in Iran. Arch Iran Med. 2014;17(4):253-7.

5. Alaizari NA, Al-Maweri SA. Oral Cancer: Knowledge, Practices and opinions of dentists in Yemen. Asian Pac J Cancer Prev. 2014;15(14):5627-31.

6. Andrade SN, Muniz LV, Soares JMA, Chaves ALF, Ribeiro RIMA. Oral cancer: assessment of knowledge and conduct of dentists in primary health care. Rev. Bras. Odontol. 2014;71(1):42-7.

7. Carrard VC, Gonçalves MR, Strey JR, Pilz C, Martins M, Martins MD, et al. Telediagnosis of oral lesions in primary care: The EstomatoNet Program. Oral Dis. 2018; 24(6):1012-19.

8. Marella GL, Raschellà F, Solinas M, Mutolo P, Potenza S, Milano F, et al. The diagnostic delay of oral carcinoma. Ig Sanita Pubbl. 2018;74(3):249-63.

9. Le Campion ACOV, Dos Santos KCB, Carmo ES, Júnior SFF, Peixoto FB, Ribeiro $\mathrm{CMB}$, et al. Characterization of diagnostic delay in oral and oropharyngeal cancer at two referral centers. Cad. Saúde Colet. 2016;24(2): 178-84.

10. SAS Institute Inc., SAS/STAT ${ }^{\circ}$ User's Guide, Version 9, Cary, NC: SAS Institute Inc., 2003.

11. Diebold S, Overbeck M. Soft Tissue Disorders of the Mouth. Emerg Med Clin North Am. 2019;37(1):55-68.

12. Sharma P, Deb T, Ray JG, Singh AK, Gupta G, Das A, et al. Oral squamous cell carcinoma profile in North-Eastern regions of India from habits to histopathology: A hospital-based study. Natl J Maxillofac Surg. 2018;9(1):56-60.
13. Alvarenga LM, MT Ruiz, Pavarino-Bertelli EC, Ruback MJC, Maniglia JV, Goloni-Bertollo EM. Epidemiologic evaluation of head and neck patients in a university hospital of Northwestern São Paulo State. Braz J Otorhinolaryngol. 2008;74(1):68-73

14. Thompson CA, Waldhör T, Schernhammer ES, Hackl M, Vutuc C, Haidinger G. Smoking and lung cancer: current trends in Austria. Wien Klin Wochenschr. 2012;124(15-16):493-9.

15. Tidwell TR, Søreide K, Hagland HR. Aging, metabolism, and cancer development: from Peto's paradox to the Warburg effect. Aging Dis. 2017;8(5):662-76. 16. Lu HJ, Yang CC, Wang LW, Chu PY, Tai SK, Chen MH, et. al. Modified weekly cisplatin-based chemotherapy is acceptable in postoperative concurrent chemoradiotherapy for locally advanced head and neck cancer. Biomed Res Int. 2015; 2015:307576

17. Lee RJ, Lee SA, Lin T, Lee KK, Christensen RE. Determining the epidemiologic, outcome, and prognostic factors of oral malignant melanoma by using the Surveillance, Epidemiology, and End Results database. J Am Dent Assoc. 2017;148(5):288-97.

18. Felippu AWD, Freire EC, Silva RA, Guimarães AV, Dedivitis RA. Impact of delay in the diagnosis and treatment of head and neck cancer. Braz J Otorhinolaryngol. 2016;82(2):140-3.

19. Chun SJ, Keam B, Heo DS, Kim KH, Sung MW, Chung EJ, et al. Optimal timing for salvage surgery after definitive radiotherapy in hypopharyngeal cancer. Radiat Oncol J. 2018;36(3):192-9.

20. Amar A, Chedid HM, Curioni OA, Dedivitis RA, Rapoport A, Cernea CR, et al. Delayed postoperative radiation therapy in local control of squamous cell carcinoma of the tongue and floor of the mouth. Einstein (São Paulo). 2014;12(4):477-9.

21. Fareed MM, Ishtiaq R, Galloway TJ. Testing the Timing: Time Factor in Radiation Treatment for Head and Neck Cancers. Curr Treat Options Oncol. 2018;19(4):17.

\section{Mini Curriculum and Author's Contribution}

1. Priscila Cristina de Paula - DDS; MSc. Contribution: planning, data acquisition, analysis, interpretation and writing o the manuscript. ORCID: 0000-00025232-9145

2. Leandro Dorigan de Macedo - DDS; PhD. Contribution: conception and planning. ORCID: 0000-0001-9708-5845

3. Soraya Fernandes Mestriner - DDS; PhD. Contribution: critical review and final approval. ORCID: 0000-0002-7482-8041

4. Hilton Marcos Alves Ricz - MD; PhD. Contribution: critical review and final approval. ORCID: 0000-0002-3019-8949

5. Daiane Leite da Roza - Stat; PhD. Contribution: statistical analysis. ORCID: 0000-0003-2911-2236

6. Luiz Carlos Conti de Freitas - MD; PhD. Contribution: critical review and final approval. ORCID: 0000-0002-2153-6512

7. Lara Maria Alencar Ramos Innocentini - DDS; PhD. Contribution: planning, analysis, interpretation, critical review and final approval. ORCID: 00000002-9899-5178

Submitted: 02/19/2019 / Accepted for publication: 04/07/2019

\section{Corresponding Author}

Lara Maria Alencar Ramos Innocentini

E-mail: linnocentini@usp.br 